\title{
Research on Cognitive Context in English Vocabulary Instruction
}

\author{
WANG Shuang, CHEN Qiang \\ Changchun University, Changchun, China
}

\begin{abstract}
Vocabulary is an important knowledge field in the foreign language teaching, however, grammatical rules are regarded as the centre of language study and learning for a long time, while vocabulary is only regarded as the filler of grammatical structures. So Grammar-Translation teaching approach is widely accepted in the foreign language teaching nowadays although it was called into question long ago. With the development of cognitive linguistics research, language is viewed as an integral part of human's general cognitive ability, and more and more researchers and applied linguists focus their attention on exploring the possibility and feasibility of employing cognitive insights into foreign language teaching. Under this background, the present thesis mainly makes an analysis of the principle of cognitive context, puts forward strategy study of cognitive context, and introduces cognitive context strategies in vocabulary teaching at last.
\end{abstract}

Keywords: context, cognitive context, vocabulary instruction, vocabulary knowledge

\section{Introduction}

In the foreign language learning, regarding the vocabulary teaching and learning as knowledge itself is correct, but it is probably defective to instill and pass the learners English vocabulary ignoring their existing language knowledge and experience. Due to the lack of a real context in the English vocabulary learning, it is important to guide the learners to construct the cognitive context of vocabulary knowledge and vocabulary understanding for teachers on vocabulary learning. Therefore, exploring the effective strategies of vocabulary teaching based on learners' language learning experience, promoting the vocabulary knowledge and the construction of meaning in English vocabulary teaching should be paid more attention to. After all, in the limited class time and space, teachers cannot put thousands of words carry on analysis and interpretation, less likely to teach students to use each of the English vocabulary.

\section{Principles of Cognitive Context in English Vocabulary Teaching}

In the English vocabulary teaching, we should make students realize that vocabulary is a symbol unit of the combination of sound and sense. The teaching of word form and word meaning is inseparable, word form and meaning are two sides, to say the word form is the word meaning, and word meaning is the word form. In order to

WANG Shuang, lecturer, master, Public Foreign Languages Teaching and Research Department, Changchun University.

CHEN Qiang, associate professor, Ph.D. candidate, Public Foreign Languages Teaching and Research Department, Changchun University. 
effectively implement the vocabulary knowledge teaching in the teaching process, the English vocabulary teaching based on the cognitive context should follow the following principles.

\section{Systemic}

The systemic of language of is accepted in the linguistic; vocabulary is one of the branch systems, but this does not deny the relevance of vocabulary system with the other branches of language system. "Language is a system composed of various subsystems, and vocabulary system is one of the important subsystems" (Aehard \& Niemeier, 2004, p. 16). Lexical semantic system depends on the relevance of other subsystems within the vocabulary and language system, and it performs in the terms of interdependent language cognitive context; Second, in order to understand and construct word knowledge effectively, the key is to referring to the cognitive system of language system, namely the encyclopedic knowledge system. We should establish the link between the lexical system and encyclopedic knowledge system in vocabulary teaching, not only their language knowledge, so we can build vocabulary knowledge effectively. Therefore, in English vocabulary teaching, systematic principle is not only referring to the knowledge system of language internal, but also involves the encyclopedic knowledge system described by vocabulary.

\section{Relevance}

The concept of "vocabulary" is a part of the study of language analysis and category, and also a schematization abstract of language analysis. In language using, words are not isolated existence, and vocabulary is undeniably rooted in the language, situational, and cultural cognitive association. In terms of cognitive context representation, we should understand and study the words in English vocabulary teaching through a variety of cognitive model, such as vocabulary category, pattern, framework, script, etc.. There is no regularity and metaphor in language vocabulary; fundamentally, it is a tool for communication, that is to say, understanding and knowing something new through the familiar things. Regardless, both inside and outside the school to any course of study, will involve our understanding of the concept, and topics related to this subject and thinking. In the process of language learning, if possible, understanding and thinking in the field of knowledge for vocabulary learning is also necessary. Many teaching is successful making concepts and vocabulary, thought and language relationship as axis; On the other hand, the English vocabulary forms a system, reflects the connection between ideas, concepts, and things. Therefore, in the process of English vocabulary teaching, it is better to reveal to learners the portrayal of vocabulary knowledge, and establish the relevance between vocabulary and knowledge, vocabulary and cognitive, words and contextual, which will make learners experience the richness of lexical meaning.

\section{Strategies of Learning Cognitive Context}

\section{Build Vocabulary Network}

The difference between Chinese learners of English and native speakers of English on vocabulary using ability is not only reflected in the number of words; more important is the quality of the vocabulary. That is to say, the learners' vocabulary knowledge has not yet formed vocabulary concept network system comprehensive and perfect as native speakers. From a macro point of view, the ultimate purpose of foreign language learning is to convey meaning and exchange ideas using a foreign language. Therefore, learners cannot satisfy to undergo 
sexual knowledge mastering English vocabulary; they should grasp the output sexual knowledge of vocabulary, so as to fully grasp the vocabulary. In the mental lexicon study, we know that the way of vocabulary in the brain tissue and the dictionary in alphabetical order are different; the arrangement of the mental lexicon of diffusion model tells us that different words are organized according to the concept of the network. In fact, the establishment of the concept of network is not limited between different vocabularies, the different meanings of the same words also exists concept network. In order to develop vocabulary ability and prevent fossilization in vocabulary acquisition, we not only should strive to establish the concept of network between different words, but also should establish the concept of polysemous word meanings between different networks. In this way, learners can establish a three-dimensional network between words and various meanings of the words, so as to develop the depth of vocabulary knowledge, and then expand their vocabulary.

\section{Deepen the Word Knowledge}

After cognitive context diversion, the knowledge constitutes context beyond language knowledge, and also puts the encyclopedic knowledge into the field of vocabulary knowledge understanding. Therefore, the understanding of vocabulary should not only stay in language understanding and knowledge involved in the vocabulary, but also involve the portrayal of encyclopedic knowledge in using the vocabulary. And encyclopedic knowledge representation in the context is not messy; according to the Langacker's point of view, encyclopedic knowledge can be divided into four categories: (1) conventional knowledge, (2) a general knowledge, (3) inner knowledge, and (4) typical knowledge. Each kind of knowledge will affect understanding and using of words. The conventional knowledge is widely known and has in common by members of a speech community, so it is more likely to occupy an important position in mental representation of the concept of vocabulary. For example, the vocabulary knowledge concept of "banana" is likely to include its color, smell, taste, and other characteristics. The use of general knowledge reflects a particular category of many examples, thus it is easy to form the conventional knowledge, such as green bananas delicious than yellow bananas for rubber color yellow is the characterization of maturity. Inner knowledge that is associated with the inherent characteristics of the things, is not affected by external environment, for example, "ball" is a circle. Typical knowledge refers to the degree of uniqueness knowledge for one type of entity, for example, "bananas can be eaten" is not typical knowledge, because the things you can eat is too much.

\section{Vocabulary Teaching Strategies of Cognitive Context}

\section{Vocabulary Associated With Cognitive Context}

As we know, vocabulary is not alone in any language, but will closely link its root social and cultural context and life practice of the speakers. The vocabulary will express the rich meaning associated with other vocabulary from the language system itself. Similarly, English vocabulary presentation can also be used in a certain context. Words appear to provide learners with "understandable input", so the situation presented by should be close to the practice of the student life, it cannot get away from life and ignore the existing language knowledge and experience. Presenting vocabulary in the situational context, we should consider the factors of relationship between the participants in the situation, the content, and the way they communicate, and correlation between vocabulary and situation used in the communication. The mediums presented are various; it can be oral and also written, a real life, and also virtual. 


\section{Teach Vocabulary Knowledge, Also Context Knowledge}

Inflected by the traditional vocabulary teaching methods based on the glossary and definition, added all levels and all kinds of foreign language curriculum standard or the syllabus stated, learners are required to reach a certain vocabulary in each period. However, people really determined to learn English well rarely have the kind of imagination "crazy". Starting from the view of cognitive context, vocabulary knowledge and encyclopedic knowledge do not exist between the division of eurabia, if a person's knowledge and thinking is very poor, it is absolutely bad to learn words. Face to face with English vocabulary teaching practice, following the footsteps of the ancient sages, combining with the present cognitive interpretation of context from the perspective of cognitive linguistics, word formation, understanding and applying all exceeds the "vision" of the word knowledge need which is also very necessary.

\section{Around the Theme, Encourage Scenario Using}

The purpose of learning vocabulary is to apply; they can belong to you only by using. However, we usually emphasize the use of vocabulary, but students do not know how and where to use. The reason is that they do not combine vocabulary with the cognitive domain it points to in learning. Therefore, for some of the basic category of vocabulary learning, teachers should encourage learners to learn vocabulary used in daily life practice, through vocabulary construction scene and situational learning vocabulary knowledge, which are complementary to each other. Teaching or teacher on the given situation, however, is very typical scenario; there is a certain distance with the daily life. We can put the seemingly unrelated words through specific topics together, through cognitive context representation, make them produce association effect, and provide a "paradigm" for us to learn vocabulary and use words. Besides, it can also organize framework of vocabulary learning according to your own life experience, and then vocabulary and life are closely linked, which successfully build the platform for words using.

\section{Conclusion}

Standing from the perspective of cognitive context, vocabulary-related embodies in vocabulary and linguistic context, vocabulary and situational context, and vocabulary and cultural context. In the process of vocabulary teaching, people emphasize vocabulary understanding and cognitive context, which embody the connection of vocabulary teaching, make learners build vocabulary knowledge effectively in the words using, restore a vivid context of English vocabulary understanding, and expand the lexical semantic network. This paper explores learners' English vocabulary learning strategies based on the cognitive context of English vocabulary teaching, and confirms the application of cognitive context in vocabulary teaching in concrete teaching case.

\section{References}

Aehard, M., \& Niemeier, S. (Eds.). (2004). Cognitive linguistics, second language acquisition, and foreign language teaching. Berlin/New York: Mounton de Gruyter.

Chris, S. (2010). Languages, culture and mind: Ten lectures on development, evolution and cognitive linguistics. Beijing: Foreign Language Teaching and Research Press.

Coady, J., \& Huckin, T. (Eds.). (1997). Second language vocabulary acquisition. Cambridge: Cambridge University Press.

Evans, V., \& Pourcel, S. (2009). New directions in cognitive linguistics. Amsterdam/Philadelphia: John Benjamins Publishing Company. 
Fauconnier, G. (2010). Ten lectures on cognitive construction of meaning (Vol. xvi). Beijing: Foreign Language Teaching and Research Press.

Hedge, T. (2008). Teaching and learning in the language classroom. Oxford: Oxford University Press.

Larsen-Freeman, N. (2003). Techniques and principles in language teaching (2nd ed.). Oxford: Oxford University Press.

Richard, J. C., Platt, J., \& Platt, H. (2003). Longman dictionary of language teaching \& applied linguistics. Beijing: Foreign Language Teaching and Research Press.

Bongers, H. (1947).The history and principle of vocabulary control. Wocopi: Woerden.

Coulson, S. (2010). Semantic leaps: Frame-shifting and conceptual blending in meaning construction. Cambridge: Cambridge University Press.

Deighton, L. C. (1959). Vocabulary development in the classroom. New York: Teacher's College Press, Columbia University.

Evans, V., \& Green, M. (2006). Cognitive linguistics: An introduction. Edinburgh: Edinburgh University Press. 